\title{
Potential roles of AMP-activated protein kinase in liver regeneration in mice with acute liver injury
}

\author{
JING HUANG $^{1 *}$, DAIJUAN ZHANG ${ }^{2 *}$, LING LIN $^{1}$, RONG JIANG $^{3}$, JIE DAI $^{4}$, \\ LI TANG $^{1}$, YONGQIANG YANG ${ }^{1}$, PU GE $^{1}$, BIN WANG ${ }^{5}$ and LI ZHANG $^{1}$ \\ ${ }^{1}$ Department of Pathophysiology, Chongqing Medical University, Chongqing 400016; ${ }^{2}$ Department of Pathophysiology, \\ Weifang Medical University, Weifang, Shandong 261053; ${ }^{3}$ Laboratory of Stem Cell and Tissue Engineering, \\ Chongqing Medical University, Chongqing 400016; ${ }^{4}$ Hospital of Chongqing University of Arts and Sciences, \\ Chongqing 402160; ${ }^{5}$ Department of Anesthesiology, The First Affiliated Hospital, \\ Chongqing Medical University, Chongqing 400016, P.R. China
}

Received November 3, 2017; Accepted January 19, 2018

DOI: $10.3892 / \mathrm{mmr} .2018 .8522$

\begin{abstract}
Liver regeneration post severe liver injury is crucial for the recovery of hepatic structure and function. The energy sensor AMP-activated protein kinase (AMPK) has a crucial role in the regulation of nutrition metabolism in addition to other energy-intensive physiological and pathophysiological processes. Cellular proliferation requires intensive energy and nutrition support, therefore the present study investigated whether AMPK is involved in liver regeneration post carbon tetrachloride $\left(\mathrm{CCl}_{4}\right)$-induced acute hepatic injury. The experimental data indicated that phosphorylation level of AMPK increased $48 \mathrm{~h}$ post- $\mathrm{CCl}_{4}$ exposure, which was accompanied with upregulation of proliferating cell nuclear antigen (PCNA) and recovery of alanine aminotransferase (ALT) level. Pretreatment with the AMPK inhibitor compound $\mathrm{C}$ had no obvious effects on ALT elevation in plasma and histological abnormalities in liver $24 \mathrm{~h}$ post $\mathrm{CCl}_{4}$ exposure. However, treatment with compound $\mathrm{C} 24 \mathrm{~h}$ post $\mathrm{CCl}_{4}$ exposure significantly suppressed $\mathrm{CCl}_{4}$-induced AMPK phosphorylation, PCNA expression and ALT recovery. These data suggest that endogenous AMPK was primarily activated at the regeneration stage in mice with $\mathrm{CCl}_{4}$-induced acute liver injury and may function as a positive regulator in liver regeneration.
\end{abstract}

Correspondence to: Dr Bin Wang, Department of Anesthesiology, The First Affiliated Hospital, Chongqing Medical University, 1 Yixueyuan Road, Chongqing 400016, P.R. China E-mail: 774935778@qq.com

Dr Li Zhang, Department of Pathophysiology, Chongqing Medical University, 1 Yixueyuan Road, Chongqing 400016, P.R. China

E-mail: zhangli@cqmu.edu.cn

*Contributed equally

Key words: AMP-activated protein kinase, liver regeneration, energy sensor, carbon tetrachloride, acute liver injury

\section{Introduction}

Acute liver injury induced by drugs, poisons or infections is a common health problem worldwide, which remains one of the leading causes of death (1). To alleviate the liver damage and improve the outcomes, extensive studies have been conducted to investigate the mechanisms underlying the development of liver injury (2-5). Importantly, the liver has strong regenerative activity after injury to compensate liver cell loss (6-8). The regeneration process is crucial for the recovery of hepatic structure and function (9-12).

AMP-activated protein kinase (AMPK) is a serine/threonine kinase. It is usually regarded as a sensor of cellular energy status used to keep up a delicate balance by monitoring both the short- and long-term total body energy requirements (13). Interestingly, recent studies have found that AMPK was extensively involved in various energy-intensive physiological and pathophysiological processes, such as inflammation (14), autophagy (15-17) and proliferation (18-21). Therefore, AMPK is rapidly emerging as a novel target for pathophysiological and pharmacological research (22).

There is increasing evidence that AMPK is involved in the development of hepatic disorders. Several studies have found that AMPK plays crucial roles in the development of cholestatic liver diseases, nonalcoholic fatty liver disease and liver fibrosis (23-25). In addition, AMPK also have potential value for the pharmacological intervention of liver injury induced by carbon tetrachloride $\left(\mathrm{CCl}_{4}\right)$, endotoxin or ischemia (26-28). Although the crucial roles of AMPK in liver injury have been reported, the pathological significance of AMPK in the regeneration stage post acute liver injury was unclear.

Because liver regeneration includes a serial of highly active molecular responses, which requires intensive energy supply (9), we then suspected that AMPK might regulate the procedure of liver regeneration. In the present study, the potential role of AMPK in liver regeneration was investigated in mice with $\mathrm{CCl}_{4}$-induced toxic liver injury (13). In this widely used animal model, the phosphorylation status of AMPK post $\mathrm{CCl}_{4}$ exposure was detected. Then, the activity of AMPK was inhibited by a selective AMPK inhibitor, 
compound C $(29,30)$, and the degree of liver regeneration was determined.

\section{Materials and methods}

Experimental animals. The male KM mice (Mus musculus $\mathrm{Km}$ ) weighing 18-22 g were purchased from the Experimental Animal Center of Chongqing Medical University (Chongqing, China). Mice were kept in a 12-h light/dark cycle with ad libitum water and food. All experimental protocols involving the animals were approved by the Institutional Animal Care and Use Committee of Chongqing Medical University.

Reagents. $\mathrm{CCl}_{4}$ was obtained from Chengdu Kelong Chemical Reagent Factory (Chengdu, China). The AMPK inhibitor F6-[4-[2-(1-piperidinyl)ethoxy]phenyl]-3(4-pyridinyl)-pyrazolo[1,5-a]pyrimidine (compound C) was purchased from Cayman Chemical (Ann Arbor, Michigan, MI, USA). The alanine aminotransferase (ALT) detection kit was purchased from Nanjing Jiancheng Bioengineering Institute (Nanjing, China). Rabbit anti-mouse antibodies against AMPK, phosphorylated AMPK (p-AMPK, Thr ${ }^{172}$ ) and $\beta$-actin were purchased from Cell signaling Technology (Danvers, MA, USA). Rabbit anti-mouse antibody against proliferating cell nuclear antigen (PCNA) antibody was purchased from Abcam (Cambridge, UK). The BCA protein assay kit, the horseradish peroxidase-conjugated goat anti-rabbit antibody and the enhanced chemiluminescence (ECL) reagents were obtained from Pierce Biotechnology (Rockford, IL, USA).

Experimental design. To induce acute liver injury, the mice received intraperitoneal injection of $\mathrm{CCl}_{4}(1 \%$, dissolved in olive oil, $0.8 \mathrm{ml} / \mathrm{kg}$ ). To determine the phosphorylation status of hepatic AMPK, the mice were anesthetized and sacrificed at various timepoints post $\mathrm{CCl}_{4}$ exposure $(0,24$ and $48 \mathrm{~h} ; \mathrm{n}=8$ for each group), the liver and plasma samples were harvested for further experiments. To investigate the potential roles of AMPK in acute liver injury, the mice were randomly divided into 4 groups ( $n=8$ for each group): i) the control (CON) group, mice received vehicle only; ii) the compound $\mathrm{C}$ group, mice received the AMPK inhibitor compound $\mathrm{C}(15 \mathrm{mg} / \mathrm{kg}$, i.p.) only; iii) the $\mathrm{CCl}_{4}$ group, mice exposed to $\mathrm{CCl}_{4}$; iv) the $\mathrm{CCl}_{4}+$ compound $\mathrm{C}$ group, mice received compound $\mathrm{C} 0.5 \mathrm{~h}$ prior to $\mathrm{CCl}_{4}$ challenge. The animals were sacrificed $24 \mathrm{~h}$ post $\mathrm{CCl}_{4}$ exposure, the liver and plasma samples were harvested. To investigate the potential roles of AMPK in liver injury, the mice were randomly divided into 4 groups $(n=8$ for each group): i) the $\mathrm{CON}$ group, mice received vehicle only; ii) the compound $\mathrm{C}$ group, mice received the $\mathrm{AMPK}$ inhibitor compound $\mathrm{C}\left(15 \mathrm{mg} / \mathrm{kg}\right.$, i.p.) only; iii) the $\mathrm{CCl}_{4}$ group, mice exposed to $\mathrm{CCl}_{4}$; iv) the $\mathrm{CCl}_{4}+$ compound $\mathrm{C}$ group, mice received compound $\mathrm{C} 24 \mathrm{~h}$ post $\mathrm{CCl}_{4}$ challenge. The animals were sacrificed $48 \mathrm{~h}$ post $\mathrm{CCl}_{4}$ exposure, the liver and plasma samples were harvested. The plasma samples were collected in the heparin tubes and were then centrifuged at 5,000 RPM for $15 \mathrm{~min}$ at $4^{\circ} \mathrm{C}$. The supernatants were collected for further examinations.

Determination of liver enzymes. The plasma samples were collected with the method described above. The levels of ALT in plasma samples were determined following the manufacturer's instructions. The enzymatic activities were calculated according to the standard curve.

Histochemistry. The liver samples were fixed in formalin, embedded in paraffin, and the liver sections were evaluated with hematoxylin and eosin staining under light microscope (Olympus Corp., Tokyo, Japan).

Immunoblot analysis. The proteins were extracted from the liver samples and the concentration of the protein samples was determined by BCA protein assay kit (Pierce Biotechnology). Protein extracts were separated on 10 or $8 \%$ SDS-PAGE gels, then transferred to nitrocellulose membrane (Millipore, Billerica, MA, USA). After incubation with the 5\% (w/v) skimmed milk in Tris-buffered saline (TBST) containing $0.1 \%$ Tween-20 for $2 \mathrm{~h}$ at room temperature, the membranes were incubated with primary antibodies overnight at $4^{\circ} \mathrm{C}$. And then, the membranes were washed by TBST (containing $0.05 \%$ Tween-20), then incubated with secondary antibody for $1.5 \mathrm{~h}$ at $37^{\circ} \mathrm{C}$ and then washed by TBST. Antibody binding was visualized with an ECL chemiluminescence system (Pierce Biotechnology).

Statistical analysis. Data were presented as mean \pm SD and analyzed by one-way ANOVA with Turkey's post hoc test in SPSS13.0. $\mathrm{P}<0.05$ was considered to indicate a statistically significant difference.

\section{Results}

$A M P K$ was activated post $C_{C} C_{4}$ challenge. The immunoblot analysis showed that $\mathrm{CCl}_{4}$ exposure did not stimulate the phosphorylation of AMPK $24 \mathrm{~h}$ post- $\mathrm{CCl}_{4}$ administration, but the phosphorylation level of AMPK was upregulated $48 \mathrm{~h}$ post- $\mathrm{CCl}_{4}$ exposure (Fig. 1). The upregulation of p-AMPK $48 \mathrm{~h}$ post- $\mathrm{CCl}_{4}$ exposure was accompanied with increased expression of PCNA and recovery of ALT level (Figs. 2 and 3).

Pre-insult treatment with an AMPK inhibitor had no obvious effects on liver injury. To determine the potential roles of AMPK on $\mathrm{CCl}_{4}$-induced liver injury, the AMPK inhibitor compound $\mathrm{C}$ was administered before $\mathrm{CCl}_{4}$ exposure. The experimental data shown that pretreatment with compound $\mathrm{C}$ had no significant effects on $\mathrm{CCl}_{4}$-induced elevation of ALT in plasma (Fig. 4). Consistently, the histopathological examination found no obvious difference in $\mathrm{CCl}_{4}$-challenged mice with or without compound $\mathrm{C}$ administration (Fig. 5).

Delayed inhibition of AMPK suppressed liver regeneration. To investigate whether AMPK is involved in liver regeneration post $\mathrm{CCl}_{4}$ challenge, compound $\mathrm{C}$ was administered $24 \mathrm{~h}$ post $\mathrm{CCl}_{4}$ exposure. The experimental data shown that post-treatment with compound $\mathrm{C}$ significantly suppressed AMPK phosphorylation $48 \mathrm{~h}$ post $\mathrm{CCl}_{4}$ exposure (Fig. 6). Post-treatment with compound $\mathrm{C}$ also suppressed $\mathrm{CCl}_{4}$-induced expression of PCNA $48 \mathrm{~h}$ post $\mathrm{CCl}_{4}$ exposure (Fig. 7). Meanwhile, the recovery of ALT level $48 \mathrm{~h}$ post $\mathrm{CCl}_{4}$ exposure was impaired by compound $\mathrm{C}$ administered post $\mathrm{CCl}_{4}$ exposure (Fig. 8). 

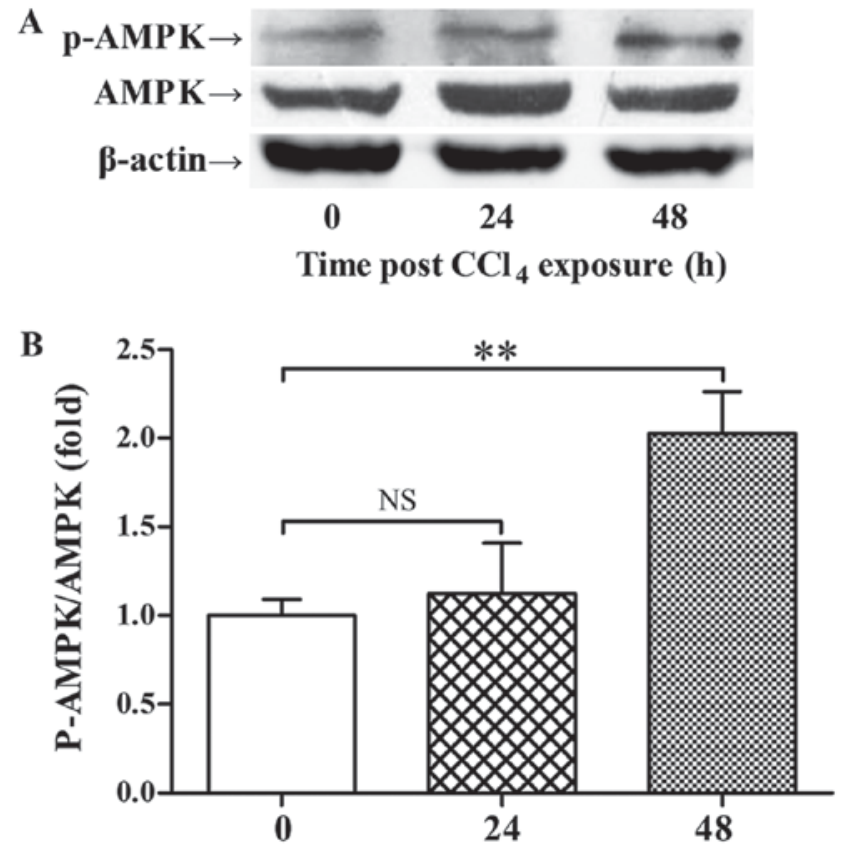

Time post $\mathrm{CCl}_{4}$ exposure (h)

Figure 1. $\mathrm{CCl}_{4}$-induced phosphorylation of AMPK in liver. Acute liver injury was induced by intraperitoneal injection of $\mathrm{CCl}_{4}$. The liver samples were harvested $0,24,48 \mathrm{~h}$ post $\mathrm{CCl}_{4}$ exposure. (A) The level of p-AMPK and total AMPK were determined by immunoblot analysis. The target proteins were indicated by arrows in the blot. (B) The bands of p-AMPK and AMPK were semi-quantified by gray scale. $n=4,{ }^{\text {NS}} \mathrm{P}>0.05,{ }^{* *} \mathrm{P}<0.01$. AMPK, AMP-activated protein kinase; CCl4, carbon tetrachloride; p-AMPK, phosphorylated AMPK.
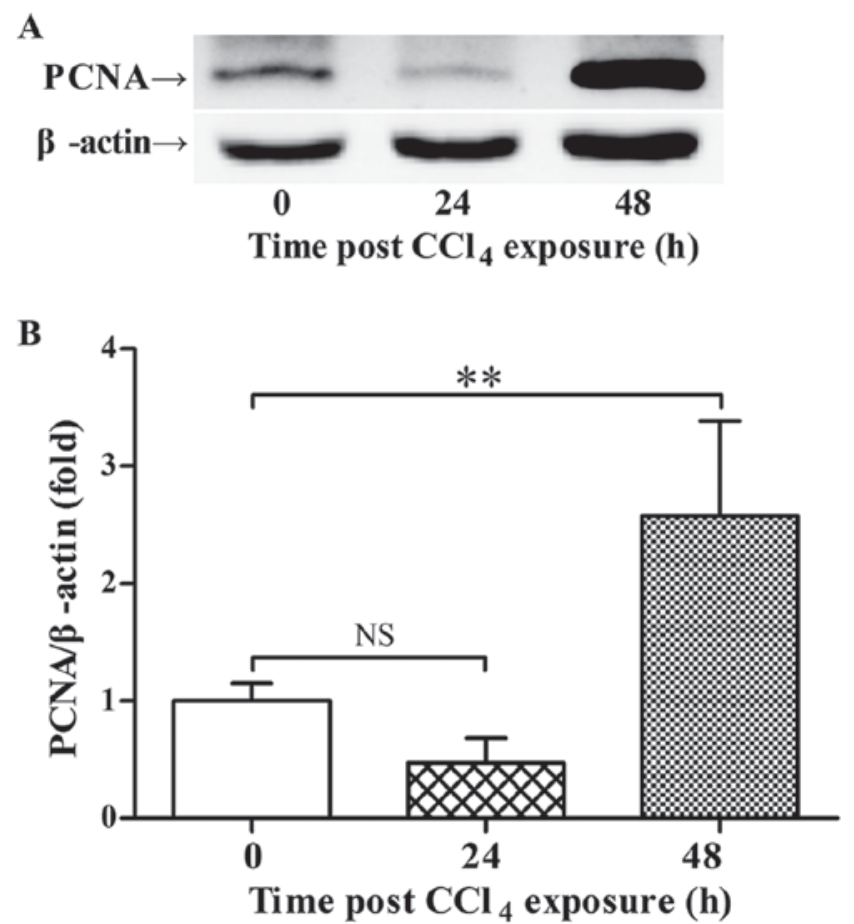

Figure 2. $\mathrm{CCl}_{4}$-induced expression of PCNA in liver. Acute liver injury was induced by intraperitoneal injection of $\mathrm{CCl}_{4}$. The liver samples were harvested $0,24,48 \mathrm{~h}$ post $\mathrm{CCl}_{4}$ exposure. (A) The level of PCNA was determined by immunoblot analysis. The target proteins were indicated by arrows in the blot. (B) The bands of PCNA and $\beta$-actin were semi-quantified by gray scale. $\mathrm{n}=4,{ }^{\mathrm{NS}} \mathrm{P}>0.05,{ }^{* *} \mathrm{P}<0.01$. CCl4, carbon tetrachloride; PCNA, proliferating cell nuclear antigen.

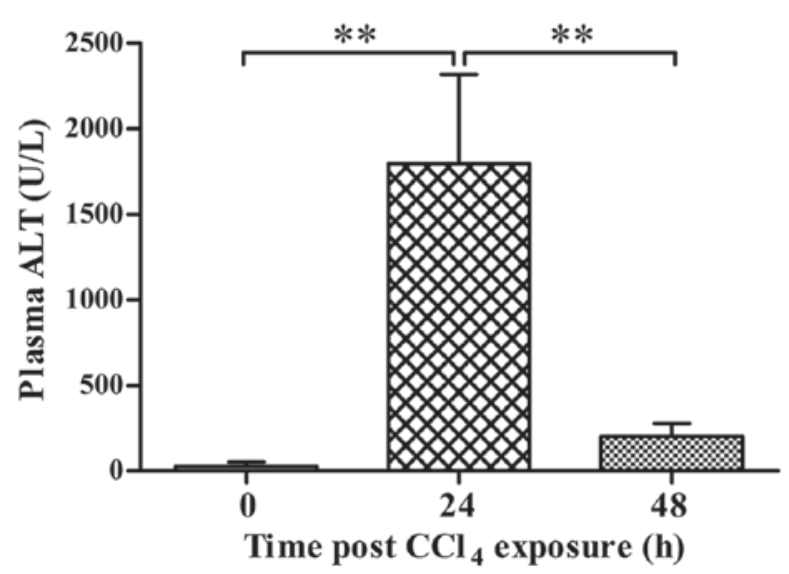

Figure 3. $\mathrm{CCl}_{4}$-induced elevation of ALT in plasma. Acute liver injury was induced by intraperitoneal injection of $\mathrm{CCl}_{4}$. The plasma samples were harvested $0,24,48 \mathrm{~h}$ post $\mathrm{CCl}_{4}$ exposure and the activity of ALT was determined. $\mathrm{n}=8,{ }^{* *} \mathrm{P}<0.01$. $\mathrm{CCl} 4$, carbon tetrachloride; ALT, alanine aminotransferase.

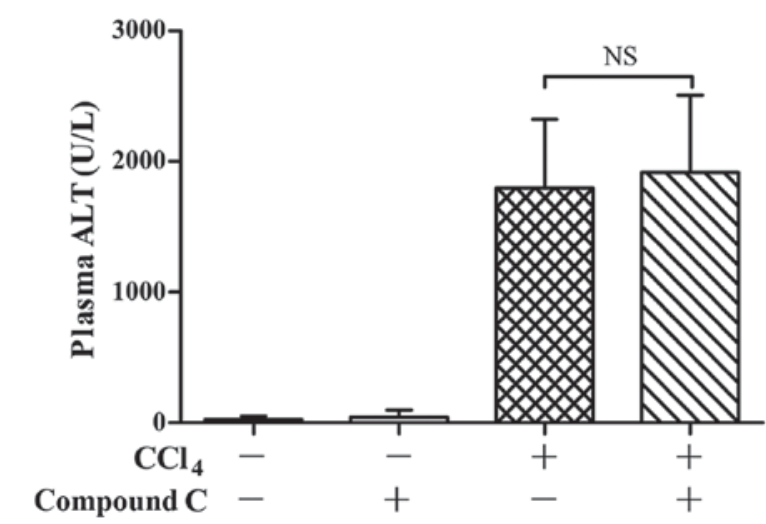

Figure 4. Pretreatment with compound $\mathrm{C}$ had no significant effects on $\mathrm{CCl}_{4}$-induced elevation of ALT in plasma. Acute liver injury was induced by intraperitoneal injection of $\mathrm{CCl}_{4}$ and the AMPK inhibitor compound $\mathrm{C}$ was administered $30 \mathrm{~min}$ before $\mathrm{CCl}_{4}$ exposure. The plasma samples were harvested $24 \mathrm{~h}$ post $\mathrm{CCl}_{4}$ exposure and the activity of ALT was determined. $\mathrm{n}=8,{ }^{\mathrm{NS}} \mathrm{P}>0.05$. AMPK, AMP-activated protein kinase; $\mathrm{CCl} 4$, carbon tetrachloride; ALT, alanine aminotransferase; compound C, F6-[4-[2-(1-piperidinyl) ethoxy]phenyl]-3-(4-pyridinyl)-pyrazolo[1,5-a]pyrimidine.

\section{Discussion}

AMPK has been regarded as a crucial metabolic regulator which plays central roles in the maintenance of energy homeostasis (22). Our previous studies have found that AMPK provided anti-inflammatory benefits in mice with acute hepatitis induced by carbon tetrachloride or endotoxin $(26,31)$. Several studies have found that AMPK was involved in the regulation of cellular proliferation (32-34). In the present study, we found that pharmacological inhibition of AMPK suppressed liver regeneration post $\mathrm{CCl}_{4}$-induced acute liver injury. Consistently, similar results have been obtained in a regenerative model with partial hepatectomy $(11,18,35)$. These data suggests that AMPK might have positive roles in liver regeneration.

$\mathrm{CCl}_{4}$ is a representative hepatotoxin which induces severe liver injury quickly, the degree of liver damage usually peaks at $24 \mathrm{~h}$ after $\mathrm{CCl}_{4}$ exposure, followed by liver regeneration and 


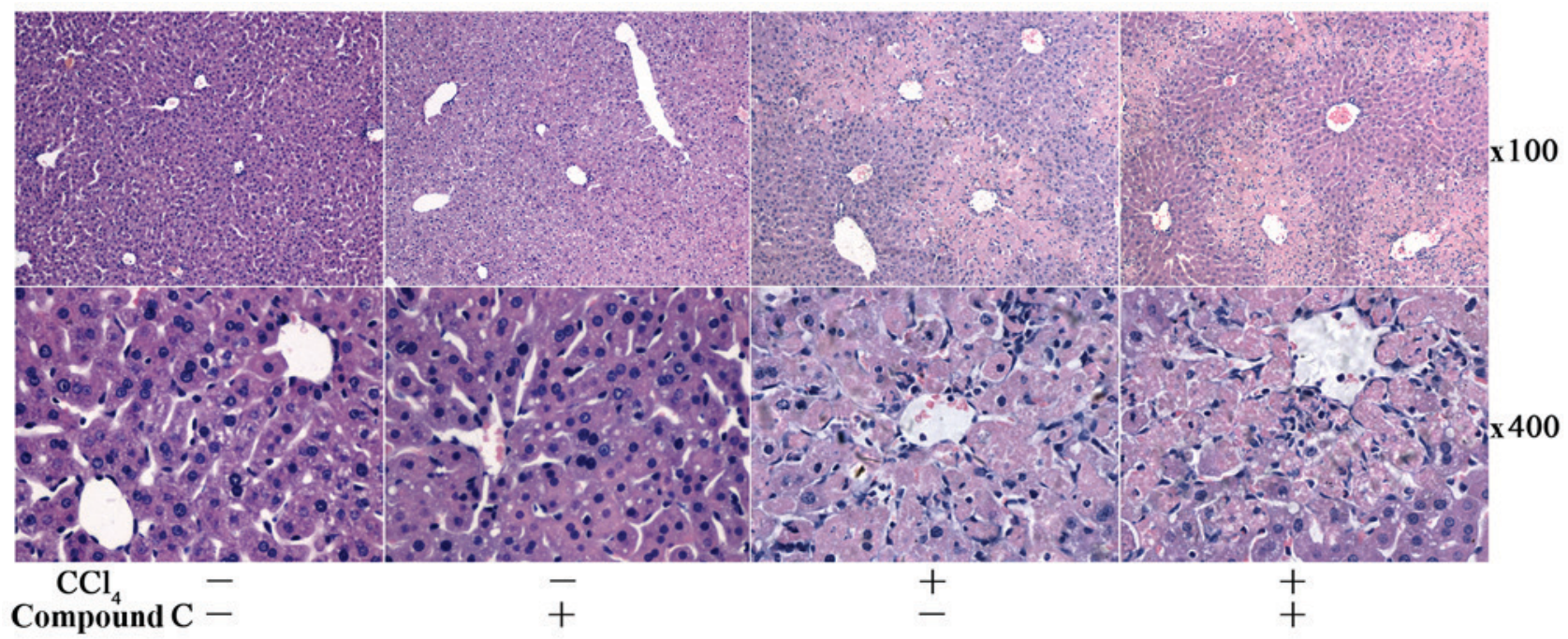

Figure 5. Pretreatment with compound $\mathrm{C}$ had no significant effects on $\mathrm{CCl}_{4}$-induced histological abnormalities in liver. Acute liver injury was induced by intraperitoneal injection of $\mathrm{CCl}_{4}$ and the AMPK inhibitor compound $\mathrm{C}$ was administered $30 \mathrm{~min}$ before $\mathrm{CCl}_{4}$ exposure. The liver samples were harvested $24 \mathrm{~h}$ post $\mathrm{CCl}_{4}$ exposure and stained with hematoxylin and eosin for morphological examination. The representative liver sections of each group were shown. AMPK, AMP-activated protein kinase; CCl4, carbon tetrachloride compound C, F6-[4-[2-(1-piperidinyl)ethoxy]phenyl]-3-(4-pyridinyl)-pyrazolo[1,5-a]pyrimidine.
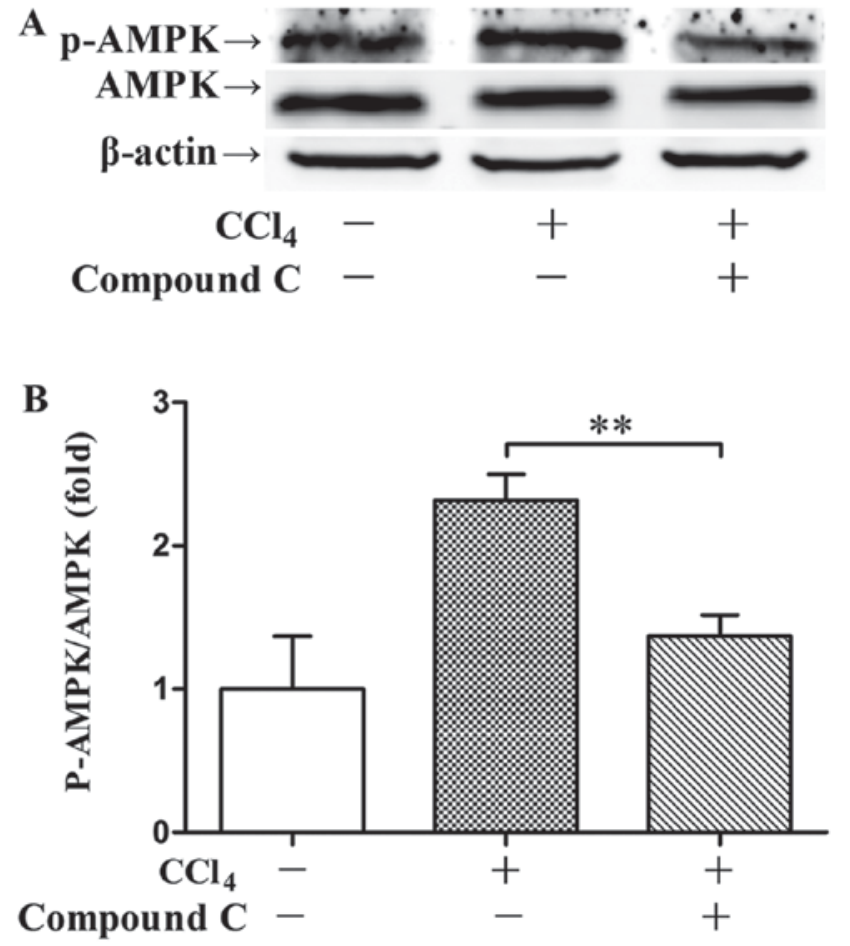

Figure 6. Post-treatment with compound $\mathrm{C}$ suppressed $\mathrm{CCl}_{4}$-induced phosphorylation of AMPK in liver. Acute liver injury was induced by intraperitoneal injection of $\mathrm{CCl}_{4}$ and the AMPK inhibitor compound $\mathrm{C}$ was administered $24 \mathrm{~h}$ post $\mathrm{CCl}_{4}$ exposure. The liver samples were harvested $48 \mathrm{~h}$ post $\mathrm{CCl}_{4}$ exposure. (A) The level of p-AMPK and total AMPK were determined by immunoblot analysis. The target proteins were indicated by arrows in the blot. (B) The bands of p-AMPK and AMPK were semi-quantified by gray scale. $n=4,{ }^{* *} \mathrm{P}<0.01$. AMPK, AMP-activated protein kinase; $\mathrm{CCl} 4$, carbon tetrachloride compound C, F6-[4-[2-(1-piperidinyl)ethoxy]phenyl]-3(4-pyridinyl)-pyrazolo[1,5-a]pyrimidine; p-AMPK, phosphorylated AMPK.

recovery (13). In the present study, the immunoblot analysis indicated that the phosphorylation level of AMPK significantly increased $48 \mathrm{~h}$ post $\mathrm{CCl}_{4}$ challenge. In another model with endotoxin-induced acute liver injury, we also found that endogenous
A

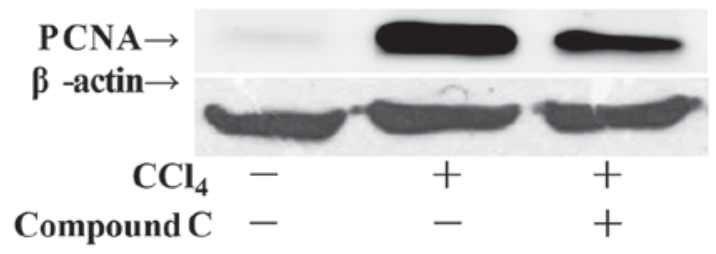

B

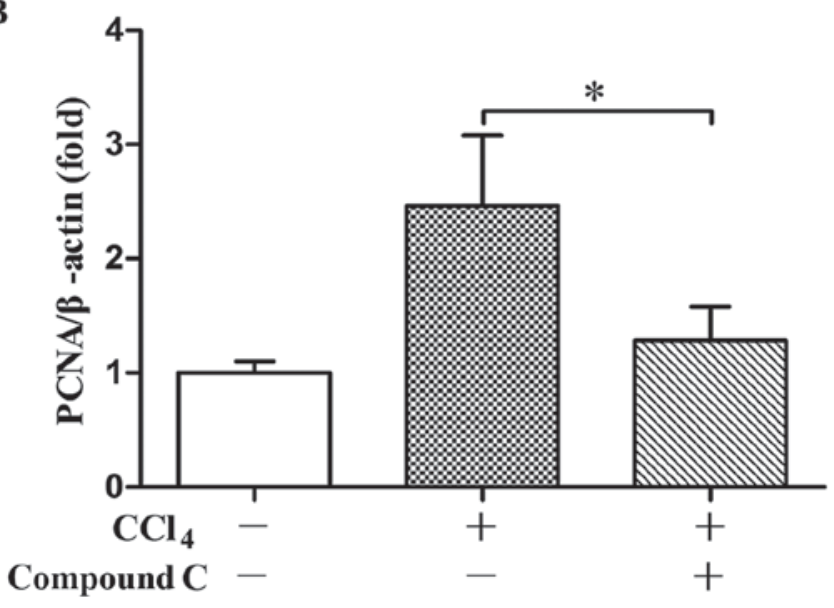

Figure 7. Post-treatment with compound $\mathrm{C}$ inhibited $\mathrm{CCl}_{4}$-induced expression of PCNA in liver. Acute liver injury was induced by intraperitoneal injection of $\mathrm{CCl}_{4}$ and the AMPK inhibitor compound $\mathrm{C}$ was administered $24 \mathrm{~h}$ post $\mathrm{CCl}_{4}$ exposure. The liver samples were harvested $48 \mathrm{~h}$ post $\mathrm{CCl}_{4}$ exposure. (A) The level of PCNA was determined by immunoblot analysis. The target proteins were indicated by arrows in the blot. (B) The bands of PCNA and $\beta$-actin were semi-quantified by gray scale. $n=4,{ }^{*} \mathrm{P}<0.05$. AMPK, AMP-activated protein kinase; $\mathrm{CCl} 4$, carbon tetrachloride; PCNA, proliferating cell nuclear antigen compound C, F6-[4-[2-(1-piperidinyl) ethoxy]phenyl]-3-(4-pyridinyl)-pyrazolo[1,5-a]pyrimidine.

AMPK was mainly phosphorylated at the late stage (36). In the present study, pretreatment with the AMPK inhibitor compound $\mathrm{C}$ had little effects on the elevation of ALT in plasma and the degree of histological abnormalities in liver. Therefore, 


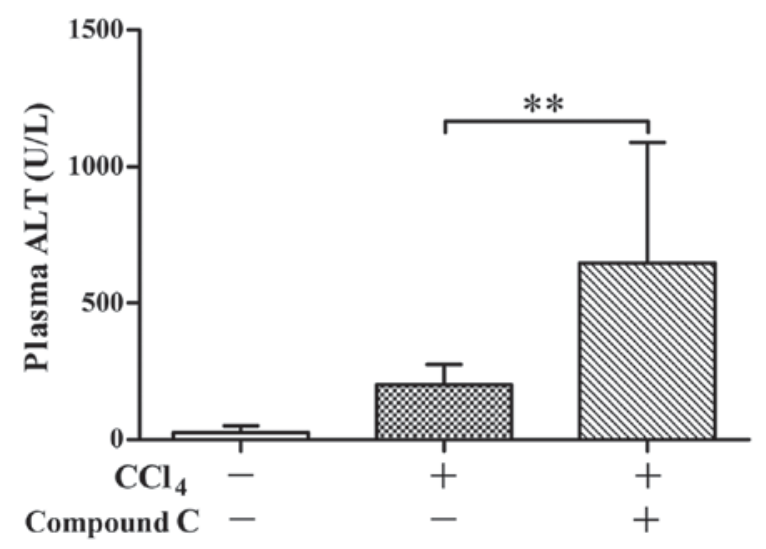

Figure 8. Post-treatment with compound $\mathrm{C}$ impaired the recovery of plasma ALT $48 \mathrm{~h}$ post $\mathrm{CCl}_{4}$ exposure. Acute liver injury was induced by intraperitoneal injection of $\mathrm{CCl}_{4}$ and the AMPK inhibitor compound $\mathrm{C}$ was administered $24 \mathrm{~h}$ post $\mathrm{CCl}_{4}$ exposure. The plasma samples were harvested $48 \mathrm{~h}$ post $\mathrm{CCl}_{4}$ exposure and the activity of ALT was determined. $\mathrm{n}=8$, ${ }^{* *} \mathrm{P}<0.01$. AMPK, AMP-activated protein kinase; $\mathrm{CCl} 4$, carbon tetrachloride; ALT, alanine aminotransferase compound C, F6-[4-[2-(1-piperidinyl)ethoxy] phenyl]-3-(4-pyridinyl)-pyrazolo[1,5-a]pyrimidine.

endogenous AMPK mainly functions at the regeneration stage in $\mathrm{CCl}_{4}$-exposed mice.

Because the phosphorylation of AMPK was associated with the expression of PCNA, a well-documented molecular marker of cellular proliferation (37), we also determined the roles of AMPK at the regeneration stage by treatment with the AMPK inhibitor $24 \mathrm{~h}$ post $\mathrm{CCl}_{4}$ exposure. The results indicated that post-insult inhibition of AMPK significantly suppressed the expression PCNA, which was accompanied with delayed decline of ALT. These data suggests that $\mathrm{CCl}_{4}$-induced activation of AMPK might act as a positive regulator in liver regeneration.

There is a considerable amount of researches have demonstrated a crucial link between AMPK and cellular proliferation (18-20). A study in cardiac fibroblasts found that AMPK suppressed cell cycle progression via modulating the expression of p21 and p27 (38). In addition, the suppressive effects of AMPK on tumor cell proliferation have been observed in neuroblastoma cells, breast cancer cells, prostate cancer cells and cervical cancer cells (39). These data suggests that activation of AMPK might prevent proliferation under some circumstance.

On the contrary, it was reported that treatment with the AMPK inhibitor compound $C$ induced cell cycle arrest and suppressed the growth of colorectal cancer cells $(40,41)$. The stimulatory actions of AMPK on proliferation were also confirmed by molecular approaches in prostate cancer cells and glioma cells $(20,42)$. In addition, the in vivo promotive activities of AMPK on regeneration were observed in mice with mitochondrial myopathy or partial hepatectomy $(19,21)$. Therefore, AMPK might have positive or negative effects on cellular proliferation in different pathological conditions.

Taken together, the present study found that endogenous AMPK was mainly activated at the regeneration stage in mice with $\mathrm{CCl}_{4}$-induced acute liver injury and it might function as a positive regulator in liver regeneration. Although the molecular mechanisms underlying the stimulatory activities of AMPK on liver regeneration remain to be further investigated, the present study suggests that AMPK might play crucial roles in the recovery of liver structure and function after severe liver damage.

\section{Acknowledgements}

The present study was supported by the grants from the Shandong Provincial Natural Science Foundation (ZR2015HL126) and the Training Program of Chongqing Medical University (no. 201419).

\section{References}

1. Hotchkiss RS and Nicholson DW: Apoptosis and caspases regulate death and inflammation in sepsis. Nat Rev Immunol 6: 813-822, 2006

2. Ikeda T: Idiosyncratic drug hepatotoxicity: Strategy for prevention and proposed mechanism. Curr Med Chem 22: 528-537, 2015.

3. Yan J, Li S and Li S: The role of the liver in sepsis. Int Rev Immunol 33: 498-510, 2014.

4. Gómez-Lechón MJ, Lahoz A, Gombau L, Castell JV and Donato MT: In vitro evaluation of potential hepatotoxicity induced by drugs. Curr Pharm Des 16: 1963-1977, 2010.

5. Li X, Akhtar S, Kovacs EJ, Gamelli RL and Choudhry MA: Inflammatory response in multiple organs in a mouse model of acute alcohol intoxication and burn injury. J Burn Care Res 32: 489-497, 2011.

6. Fausto N, Campbell JS and Riehle KJ: Liver regeneration. Hepatology 43 (2 Suppl 1): S45-S53, 2006.

7. Fausto $\mathrm{N}$ and Campbell JS: The role of hepatocytes and oval cells in liver regeneration and repopulation. Mech Dev 120: 117-130, 2003.

8. Michalopoulos GK and DeFrances MC: Liver regeneration. Science 276: 60-66, 1997.

9. Hardie DG, Ross FA and Hawley SA: AMPK: A nutrient and energy sensor that maintains energy homeostasis. Nat Rev Mol Cell Biol 13: 251-262, 2012

10. Yamamoto T, Kojima T, Murata M, Takano K, Go M, Hatakeyama N, Chiba H and Sawada N: p38 MAP-kinase regulates function of gap and tight junctions during regeneration of rat hepatocytes. J Hepatol 42: 707-718, 2005.

11. Yan XP, Wang S, Yang Y and Qiu YD: Effects of n-3 polyunsaturated fatty acids on rat livers after partial hepatectomy via LKB1-AMPK signaling pathway. Transplant Proc 43: 3604-3612, 2011.

12. Li G and G LG: Farnesoid X receptor, the bile acid sensing nuclear receptor, in liver regeneration. Acta Pharm Sin B 5: 93-98, 2015.

13. Li SQ, Zhu S, Wan XD, Xu ZS and Ma Z: Neutralization of ADAM8 ameliorates liver injury and accelerates liver repair in carbon tetrachloride-induced acute liver injury. J Toxicol Sci 39: 339-351, 2014

14. Sun H, Zhu X, Lin W, Zhou Y, Cai W and Qiu L: Interactions of TLR 4 and PPAR $\gamma$, dependent on AMPK signalling pathway contribute to anti-inflammatory effects of vaccariae hypaphorine in endothelial cells. Cell Physiol Biochem 42: 1227-1239, 2017.

15. Zhang L, Fang Y, Cheng X, Lian Y, Xu H, Zeng Z and Zhu H: TRPML1 participates in the progression of alzheimer's disease by regulating the PPAR $\gamma /$ AMPK/Mtor signalling pathway. Cell Physiol Biochem 43: 2446-2456, 2017.

16. Yang F, Zhang L, Gao Z, Sun X, Yu M, Dong S, Wu J, Zhao Y, $\mathrm{Xu} \mathrm{C}$, Zhang W and Lu F: Exogenous H2S protects against diabetic cardiomyopathy by activating autophagy via the AMPK/mTOR pathway. Cell Physiol Biochem 43: 1168-1187, 2017.

17. Kemp BE, Mitchelhill KI, Stapleton D, Michell BJ, Chen ZP and Witters LA: Dealing with energy demand: The AMP-activated protein kinase. Trends Biochem Sci 24: 22-25, 1999.

18. Varela-Rey M, Beraza N, Lu SC, Mato JM and Martinez-Chantar ML: Role of AMP-activated protein kinase in the control of hepatocyte priming and proliferation during liver regeneration. Exp Biol Med (Maywood) 236: 402-408, 2011. 
19. Merlen G, Gentric G, Celton-Morizur S, Foretz M, Guidotti JE, Fauveau V, Leclerc J, Viollet B and Desdouets C: AMPK $\alpha 1$ controls hepatocyte proliferation independently of energy balance by regulating Cyclin A2 expression. J Hepatol 60: 152-159, 2014.

20. Park HU, Suy S, Danner M, Dailey V, Zhang Y, Li H, Hyduke DR, Collins BT, Gagnon G, Kallakury B, et al: AMP-activated protein kinase promotes human prostate cancer cell growth and survival. Mol Cancer Ther 8: 733-741, 2009.

21. Peralta S, Garcia S, Yin HY, Arguello T, Diaz F and Moraes CT: Sustained AMPK activation improves muscle function in a mitochondrial myopathy mouse model by promoting muscle fiber regeneration. Hum Mol Genet 25: 3178-3191, 2016.

22. Cotan D, Paz MV, Alcocer-Gomez E, Garrido-Maraver J, Oropesa-Ávila M, de la Mata M, Pavón AD, de Lavera I, Galán F, Ybot-González P and Sánchez-Alcázar JA: AMPK as a target in rare diseases. Curr Drug Targets 17: 921-931, 2016.

23. Li X, Liu R, Zhang L and Jiang Z: The emerging role of AMP-activated protein kinase in cholestatic liver diseases. Pharmacol Res 125: 105-113, 2017.

24. Woods A, Williams JR, Muckett PJ, Mayer FV, Liljevald M, Bohlooly-Y M and Carling D: Liver-specific activation of AMPK prevents steatosis on a high-fructose diet. Cell Rep 18 3043-3051, 2017

25. Liang Z, Li T, Jiang S, Xu J, Di W, Yang Z, Hu W and Yang Y: AMPK: A novel target for treating hepatic fibrosis. Oncotarget 8 : 62780-62792, 2017.

26. Yang C, Gong X, Ai Q, Ge P, Lin L and Zhang L: 5-Amino midazole-4-carboxamide-1- $\beta$-d-ribofuranoside alleviated carbon tetrachloride-induced acute hepatitis in mice. Int Immunopharmacol 25: 393-399, 2015.

27. Zhou D, Ai Q, Lin L, Gong X, Ge P, Che Q, Wan J, Wen A and Zhang L: 5-Aminoimidazole-4-carboxamide-1- $\beta$-D-ribofura noside-attenuates LPS/D-Gal-induced acute hepatitis in mice. Innate Immun 21: 698-705, 2015

28. Zhang M, Yang D, Gong X, Ge P, Dai J, Lin L and Zhang L: Protective benefits of AMP-activated protein kinase in hepatic ischemia-reperfusion injury. Am J Transl Res 9: 823-829, 2017.

29. Jin J, Mullen TD, Hou Q, Bielawski J, Bielawska A, Zhang X, Obeid LM, Hannun YA and Hsu YT: AMPK inhibitor Compound $\mathrm{C}$ stimulates ceramide production and promotes Bax redistribution and apoptosis in MCF7 breast carcinoma cells. J Lipid Res 50: 2389-2397, 2009.

30. Zhou G, Myers R, Li Y, Chen Y, Shen X, Fenyk-Melody J, Wu M, Ventre J, Doebber T, Fujii N, et al: Role of AMP-activated protein kinase in mechanism of metformin action. J Clin Invest 108 $1167-1174,2001$

31. Yuan H, Li L, Zheng W, Wan J, Ge P, Li H and Zhang L: Antidiabetic drug metformin alleviates endotoxin-induced fulminant liver injury in mice. Int Immunopharmacol 12 : 682-688, 2012
32. Shackelford DB and Shaw RJ: The LKB1-AMPK pathway: Metabolism and growth control in tumour suppression. Nat Rev Cancer 9: 563-575, 2009.

33. Vazquez-Martin A, López-Bonet E, Oliveras-Ferraros C, Pérez-Martínez MC, Bernadó L and Menendez JA: Mitotic kinase dynamics of the active form of AMPK (phospho-AMPKalphaThr172) in human cancer cells. Cell Cycle 8: 788-791, 2009.

34. Vazquez-Martin A, Oliveras-Ferraros C, Cufi S and Menendez JA: Polo-like kinase 1 regulates activation of AMP-activated protein kinase (AMPK) at the mitotic apparatus. Cell Cycle 10: 1295-1302, 2011.

35. Vazquez-Chantada M, Ariz U, Varela-Rey M, Embade N, Martínez-Lopez N, Fernández-Ramos D, Gómez-Santos L, Lamas S, Lu SC, Martínez-Chantar ML and Mato JM: Evidence for LKB1/AMP-activated protein kinase/endothelial nitric oxide synthase cascade regulated by hepatocyte growth factor, $\mathrm{S}$-adenosylmethionine and nitric oxide in hepatocyte proliferation. Hepatology 49: 608-617, 2009.

36. Cai L, Hu K, Lin L, Ai Q, Ge P, Liu Y, Dai J, Ye B and Zhang L: AMPK dependent protective effects of metformin on tumor necrosis factor-induced apoptotic liver injury. Biochem Biophys Res Commun 465: 381-386, 2015.

37. Zhang T, Guo P, Zhang Y, Xiong H, Yu X, Xu S, Wang X, He D and Jin X: The antidiabetic drug metformin inhibits the proliferation of bladder cancer cells in vitro and in vivo. Int J Mol Sci 14: 24603-24618, 2013.

38. Qi H, Liu Y, Li S, Chen Y, Li L, Cao Y, E M, Shi P, Song C, $\mathrm{Li}$ B and Sun H: Activation of AMPK attenuated cardiac fibrosis by inhibiting CDK2 via p21/p27 and miR-29 family pathways in rats. Mol Ther Nucleic Acids 8: 277-290, 2017.

39. Liu PF, Hsu CJ, Tsai WL, Cheng JS, Chen JJ, Huang IF, Tseng HH, Chang HW and Shu CW: Ablation of ATG4B suppressed autophagy and activated AMPK for cell cycle arrest in cancer cells. Cell Physiol Biochem 44: 728-740, 2017.

40. Yang WL, Perillo W, Liou D, Marambaud P and Wang P: AMPK inhibitor compound $\mathrm{C}$ suppresses cell proliferation by induction of apoptosis and autophagy in human colorectal cancer cells. J Surg Oncol 106: 680-688, 2012.

41. Viswakarma N, Jia Y, Bai L, Gao Q, Lin B, Zhang X, Misra P, Rana A, Jain S, Gonzalez FJ, et al: The Med1 subunit of the mediator complex induces liver cell proliferation and is phosphorylated by AMP kinase. J Biol Chem 288: 27898-27911, 2013.

42. Vucicevic L, Misirkic M, Janjetovic K, Harhaji-Trajkovic L, Prica M, Stevanovic D, Isenovic E, Sudar E, Sumarac-Dumanovic M, Micic D and Trajkovic V: AMP-activated protein kinase-dependent and -independent mechanisms underlying in vitro antiglioma action of compound $\mathrm{C}$. Biochem Pharmacol 77: 1684-1693, 2009. 